\section{A crise estratégica e a privatização das telecomunicações: - mal-estar da Escola Superior de Guerra}

Adriano Machado Santana ${ }^{1}$ Aluno do Prog. de Pós-graduação da FAMECOS/PUCRS Jacques Alkalai Wainberg ${ }^{2}$ Prof. Dr. do Prog. de Pós-graduação da FAMECOS/PU-

\section{Resum•}

NA DÉCADA DE 90, o Brasil testemunhou a retomada pela iniciativa privada de setores produtivos que se encontravam sob a tutela do Estado.

Este estudo avalia a posição dos estrategistas da Escola Superior de Guerra (ESG) neste período e nestas circunstâncias no que se refere à estrutura das telecomunicações no país. Cabe lembrar que até os anos 80, o entendimento dos estudiosos daquela Instituição privilegiavam a concentração do poder em torno de um Estado forte e autoritário. Em decorrência, não aceitavam a fragmentação do Sistema Nacional de Telecomunicações visto como elemento decisivo na mobilização do país e expressão de sua soberania.

Será possível observar que a noção de continuidade do monopólio e da exploração estatal dos serviços de telecomunicações (entre outros existentes), defendida de forma consensual pela doutrina militar esboçada desde os anos 50 permanece inalterada, apesar da emergência de algumas poucas vozes favoráveis às privatizações nesta comunidade.

A partir da Administração Collor, o novo entendimento do Poder Executivo brasileiro nos diferentes governos que se sucederam tem afirmado que recai sobre o País a ameaça de uma convulsão social caso os investimentos básicos em infra-estrutura não sejam realizados imediatamente, independente de quem seja o responsável pela implantação e execução dos projetos: poder público ou privado.

Tal avaliação disponível à privatiza- 
ção de bens antes monopolizados pelo Estado encontrou tão somente um discreto eco entre os iniciados na doutrina consolidada pela Escola Superior de Guerra (ESG). O documento "Contrato com o Brasil", assinado em 1996 pela Associação dos Diplomados da Escola Superior de Guerra (Adesg), é uma das poucas manifestações nesta direção.

Este interesse revelado pelos militares por temas relativos a políticas destinadas aos setores estratégicos civis não deve surpreender. Ele se constitui, na verdade, num fenômeno cujas raízes estão fincadas no alvorecer da história do Brasil.

No caso específico do nosso estudo, não são poucas as evidências do interesse histórico dos militares brasileiros pela comunicação de longa-distância, assunto que sempre e pioneiramente envolveu a comunidade da caserna. ${ }^{3}$ Neste sentido, comunicação foi sempre entendida como instrumento decisivo para a mobilização e o controle dos destinos da pátria.

Os registros de intervenção militar em nome do desenvolvimento já são contemporâneos a Euzébio de Queiroz, então ministro da Justiça, em $1848 .{ }^{4}$ Como nos demonstra Fernando de Azevedo, outra evidência que reforça a participação das Forças Armadas como um ator interessado em definir tais políticas ${ }^{5}$ é a fundação da Escola Central (século XIX), um estabelecimento militar encarregado de formar profissionais técnicos indispensáveis à solução material dos problemas de mineração. Rompia-se ali com a tradição jesuítica do ensino, que se mostrava eminentemente literária, em detrimento das ciências físicas e naturais.

Este espírito se consolidaria nos anos seguintes e era defendido com vigor na imprensa no fim dos anos 40. No entender do coronel Edmundo de Macedo Soares e Silva ${ }^{6}$, apenas ações dessa magnitude poderiam reverter o atraso tecnológico do País, em relação à extração mineral, à construção de estradas, à capacidade industrial e à formação e aperfeiçoamento de mão-de-obra de todos os setores produtivos, sobretudo.
Mas a base dessas intervenções remonta aos primeiros anos após a descoberta do Brasil. A noção de que o Exército deveria preocupar-se com a segurança e, mais tarde, com o progresso encontra-se ainda na fase colonial do Brasil. Os registros dessa formação precoce aparecem já nas primeiras décadas após a chegada da esquadra de Pedro Alvares Cabral à costa brasileira.

Este processo vai se intensificar no século XIX, ao surgirem as primeiras escolas técnicas militares. O resultado dessa decisão foi integrar a corporação militar nos objetivos civis de construção e desenvolvimento da infra-estrutura do país.

Fernando de Azevedo, em sua obra "A Cultura Brasileira",7 mostra-nos que, primeiro, tivemos uma formação intelectual eminentemente literária, obtida nos colégios de jesuítas e nos seminários. Nesse período, “a orientação recebida não visava à técnica e à ação, mas preocupava-se apenas com o cuidado com a forma, com o adestramento da eloqüência e com o exercício das funções dialéticas do espírito", o que "não podia fazer desses mestres em artes licenciados senão letrados, imitadores e eruditos, cujo maior prazer intelectual consistia no contato com os velhos autores latinos." ${ }^{8}$

A expulsão dos jesuítas, em 1759, pelo Marquês de Pombal, não conduziu à solução do problema. Com a retirada dos padres, a situação da formação intelectual e técnica dos estudantes da época piorou, pois em vez da Coroa complementar a medida substituindo a fórmula utilizada na educação, o que houve foi um desmantelamento total das instituições de ensino.

Foi somente 50 anos depois da expulsão dos docentes católicos que se deu esta restruturação, dessa vez aliado a outro tipo de cultura, voltada à preparação profissional de militares, advogados, médicos e engenheiros. A nova safra de homens, na opinião do coronel Silva, ${ }^{9}$ substituiu, aos poucos, o completo descaso pelas ciências físicas e naturais, agravada pelo horror que os cidadãos nutriam pelo trabalho manual, considerado indigno àquela época. 
Antes dessa transformação na estrutura do ensino, ainda segundo Soares, ${ }^{10}$ o que as escolas ofereciam à sociedade eram homens habilitados a preencherem vagas de funcionários públicos, em detrimento da formação de técnicos, engenheiros, naturalistas, físicos e químicos, capazes de estudar e resolver os problemas locais, de acordo com o meio circundante.

Silva, como testemunha estratégica de um tempo, define a deficiência na formação profissional até o século XVIII e sugere a solução do problema do atraso tecnológico vivenciado pelo Brasil há aproximadamente 50 anos nos seguintes termos:

"O lapso na constituição de nossas elites dirigentes deixou-nos desarmados diante do progresso industrial moderno e nos impõe a necessidade imperiosa de atacar o problema com toda a energia, se queremos sobreviver e prosperar, num mundo em que a competição é áspera e contínua. $\mathrm{O}$ progresso tecnológico é, atualmente, a pedra de toque na organização da vida de um povo. Sem ela não há estrutura econômica sólida possível, e, sem essa, não há organização política estável. A primeira preocupação, portanto, deve ser a de dar à Nação uma base econômica, sobre a qual ela possa viver e expandir seus anseios de vida digna e proveitosa, em que a todos é facultada a aspiração de progredir, intelectual e materialmente. E para isso é fundamental a formação dos homens de direção superior, com base científica e tecnológica suficiente para as grandes tarefas impostas pela vastidão e complexidade dos problemas que, na época atual, assoberbam a Nação". ${ }^{11}$

O debate em torno da situação brasileira e a percepção de seu atraso tecnológico em relação a outros países autorizou a participação ainda mais intensa dos militares na discussão dos rumos que o País deveria seguir.

$\mathrm{Na}$ época, dentre as instituições mais conhecidas e representativas deste setor encontrava-se a já referida Escola Central, que posteriormente originou a Escola Militar. Daí para frente, e com a ação efetiva dos militares na preparação de mão de obra técnica especializada, compreende-se que eles tenham atuado ativamente e crescentemente nos estudos e projetos de desenvolvimento que culminariam, a partir de 1964, com as encampações das aproximadamente 1000 empresas de telecomunicação espalhadas em todo o país.

Como dito, a partir dos anos 50, o interesse da corporação pelos temas civis não tinha diminuído e encontraria expressão adicional na criação da ESG.

Desde sua origem, entre seus objetivos estava, além de realizar estudos estratégicos, também a de prover uma liderança intelectual ao exército brasileiro e ao país, assim como criar raízes na sociedade civil. Fundada em 1948, a Escola nasceu do contato de integrantes da Força Expedicionária Brasileira com o Quarto Exército Americano, ambos enviados à Itália, na Segunda Guerra Mundial.

Ao longo de sua história, a 'Sorbone brasileira', como é conhecida, se comprometeu portanto com o recrutamento e treinamento de uma "elite" governante. Em outras palavras, sua função principal era (e continua sendo) preparar quadros capazes de elaborar e/ou executar programas nacionais de desenvolvimento.

Segundo o ex-presidente Castelo Branco, em conferência à imprensa em 14 de maio de 1964, a ESG exerceu influência extraordinária na formação do governo revolucionário. Na opinião do militar, que governou o País de 15 de abril de 1964 a 15 de março de 1967, as soluções práticas elaboradas para enfrentar os problemas nacionais estavam completamente isentas de interesses partidários. "Eles (os estrategistas) tinham aprendido a trabalhar como um time, e tiveram uma perspectiva global das questões que permeiam o futuro da nação." 12

A ESG foi criada oficialmente pelo Decreto 25705, e foi considerada a primeira instituição brasileira constituída para pensar as estratégias de Segurança e Desenvolvimento. 
De acordo com a doutrina da Escola, Segurança Nacional é "o grau relativo de garantia política, econômica, psicossocial, e militar que o estado provê, em um determinado momento, a fim de garantir a consecução dos objetivos nacionais". ${ }^{13}$

Mais tarde, o binômio Segurança e Desenvolvimento seria invertido para Desenvolvimento e Segurança, revelando alteração da doutrina no que se refere às prioridades estratégicas da nação. De qualquer forma, seu poder de influência nas políticas implementadas pelo Estado seriam especialmente fortes a partir de 1964, com a vitória da golpe civil-militar contra o governo de João Goulart, derrubado do poder em 31 de março daquele ano.

O novo regime promoveu nos anos seguintes desenvolvimento da infra-estrutura industrial e de serviços por meio da adoção de uma nova ordem econômica e política baseada na doutrina da ESG.

Acolhida e desenvolvida nos anos 50, esta doutrina tornou-se a justificativa ideológica para as práticas desenvolvimentistas - sobretudo em relação à infra-estrutura.

Neste regime, foi estimulado o desenvolvimento de tecnologias de ponta em várias áreas: telecomunicações, transporte, energia, petróleo e indústria aeroespacial. Segundo o programa "Metas e Bases para a Ação do Governo", ${ }^{14}$ o setor de telecomunicações se constituiu em um dos projetos prioritários do Estado, tendo recebido expressiva dotação orçamentária. A meta era oferecer serviços de alta qualidade e elevada confiabilidade, abrangendo telefonia, telegrafia, telex, fac-símile, transmissão de dados e de programas de alta fidelidade, além de programas de televisão.

Desde 1962, depois da aprovação da Lei 4.117, denominada Código Brasileiro de Telecomunicações (CTB) - um projeto de inspiração militar, plenamente identificado com as teses de integração nacional, territorial, segurança e desenvolvimento, elaborado no Núcleo de Estudos da ESG - a Autoridade passa a incentivar a formação das cadeias nacionais de TV concedendo subsídios no uso dos satélites e apoio aos fabricantes de equipamentos para esta indústria.

Este foi o primeiro passo para ordenar o desenvolvimento das telecomunicações no Brasil. O Código foi responsável pela transformação radical deste setor, disciplinando os serviços telefônicos e colocandoos sob o controle da autoridade federal.

O País dispunha, até então, para as comunicações nacionais de um acanhado sistema de microondas interligando Rio, São Paulo, Belo Horizonte e Brasília, extremamente congestionado.

Ao explicar a difícil situação dos serviços telefônicos no início da década de 70, Haroldo Corrêa de Mattos, ex-ministro das Comunicações, dizia à época que a Embratel voltou-se inteiramente para o Sistema Básico, com o objetivo de dotar o País de infra-estrutura de telecomunicações interestaduais e internacionais. O esforço esbarrava em uma telefonia urbana e local de baixa qualidade, geradora de graves problemas operacionais. De acordo com Matos, a situação levou o Governo a optar pela estatização das concessionárias.

A Telebrás foi criada em 1972, com o encargo de planejar e executar o controle das telecomunicações de interesse nacional, chegando a controlar $95 \%$ dos terminais instalados. Em cinco anos de atuação, o número de terminais instalados ampliou-se de 1,69 para 4,44 milhões. Seguindo orientação do Ministério das Comunicações, a Telebrás deu prioridade à aquisição de equipamentos das indústrias nacionais.

Apesar das expansões expressivas e aceleradas que ocorreram entre 1971 e $1975,{ }^{15}$ o País encontrava-se distante de atingir os índices compatíveis com suas necessidades. Nesse período, segundo dados da própria Telebrás, a planta telefônica brasileira passou de 1,4 milhões para 5 milhões de terminais instalados.

As estatísticas revelam que os recursos disponíveis para investir em comunicação não eram suficientes. A anemia dos investimentos ao longo do tempo fez com 
que o Brasil despencasse na lista dos países que mais têm linhas telefônicas por grupo de 100 habitantes. Em 1978, o Brasil era o quinto colocado. Dezenove anos depois, em 1997, caíra para a $42^{a}$ posição, numa relação de 47, à frente apenas de Irã, Egito, Tailândia, China e Índia. A partir de 1990, a opinião pública reconhecia o fato de que o Estado não reunia condições de aportar recursos para atender aos serviços básicos e menos ainda para manter-se atualizado em relação às novas tecnologias emergentes.

A Embratel primeiro, e a Telebrás depois, tinham conseguido dotar o país de uma infra-estrutura razoavelmente moderna de comunicações. Foi assim que surgiram as antenas de satélites em Itaboraí, no Estado do Rio de Janeiro, o sistema de discagem de longa distância e um quadro de técnicos capacitados a operar as telecomunicações. "Antes disso, as empresas precisavam pagar garotos para ficar o dia todo ao telefone esperando linha", segundo o jornalista Ethevaldo Siqueira, diretor da RNT. ${ }^{16}$

A decadência veio nos anos 80 , quando o Estado revelou, como dito, incapacidade gerencial e financeira para expandir a rede e acolher as novas tecnologias de comunicação. "O governo passou a cortar os investimentos, confiscou os recursos do Fundo Nacional de Telecomunicações e aviltou as tarifas", ${ }^{17}$ diz Siqueira.

“De 1985 para cá, a direção da holding e das companhias estaduais tornaramse pasto para os negócios e para a clientela de políticos. Por conta dessa aberração, $80 \%$ dos investimentos são decididos por pessoas estranhas ao setor," denuncia ele.

O mesmo ar de desânimo era refletido por declarações de militares que lamentavam o fato das telecomunicações brasileiras estarem voltando ao nível do qual saíram.

O processo de privatização começou em 1990 com o Programa Nacional de Desestatização (PND). Mais de 60 empresas estatais foram vendidas desde então e seis trechos da Rede Ferroviária Federal (RFFSA) foram concedidas a interesses privados assim como várias participações minori- tárias em outras empresas. O valor total arrecadado pelo governo foi de US\$ 26,192 bilhões (US\$ 16,726 bilhões pela venda das empresas e concessões, US\$ 619 milhões pela venda de participações minoritárias e US\$ 8,847 bilhões pela transferência de dívidas aos novos proprietários). Esses números se referem às privatizações comandadas pelo governo federal por meio do BNDES. Somam-se a essas as privatizações e concessões estaduais e a receita obtida com a venda das empresas de telecomunicações.

O processo de privatização das empresas de telecomunicações foi garantido em julho de 1997, com a aprovação da Lei Geral das Telecomunicações, que autorizou o governo federal a vender todo o sistema Telebrás, avaliado inicialmente em cerca de US\$ 100 bilhões. A Lei também criou a Agência Nacional de Telecomunicações, vinculada ao Ministério das Comunicações, para estabelecer regras e fiscalizar o setor. A permissão para a quebra do monopólio estatal de telecomunicações, com a participação de empresas nacionais e estrangeiras, foi dada pela Emenda Constitucional n. ${ }^{\circ} 8$ de 1995.

Já em julho de 1997 o governo começou a privatização da telefonia móvel. Os consórcios entregaram as propostas para a banda B em todo o país, e algumas concessionárias foram definidas. $\mathrm{O}$ consórcio $\mathrm{BCP}$, por exemplo, ganhou a concorrência para a região da Grande São Paulo e o Americel, para a Região Centro-Oeste. A banda A permaneceu sendo operada por empresas públicas, até julho de 1998.

Em outubro de 1997, a Telebrás foi dividida em 12 empresas - três de telefonia fixa e nove de telefonia celular. As três empresas de telefonia fixa são a Tele Norte, que abrange Amazonas, Roraima, Amapá, todos os estados do Nordeste e mais Rio de Janeiro, Espírito Santo e Minas Gerais; a Tele Centro-Sul, que engloba as regiões Centro-Oeste, Sul, e os estados do Tocantins, do Acre e de Rondônia; e a Telesp, que atua em São Paulo. Com 5 milhões de linhas, a Telesp tem sozinha o porte das ou- 
tras duas holdings do sistema. Essas empresas foram privatizadas em agosto de 1998.

Um dos pilares da atual política econômica, a privatização é utilizada pelo governo federal para reequilibrar as contas públicas, reduzindo a dívida do setor público e aumentando a captação de recursos externos. O governo argumenta que a nova conjuntura mundial exigiria pesados investimentos para garantir a competitividade de empresas petroquímicas, telefônicas, siderúrgicas, mineradoras, ferroviárias e outras perante o mercado internacional.

A documentação produzida pela ESG a partir dos anos 90 apresenta um elenco de queixas que deixa transparecer um malestar generalizado com este redesenho libe$\mathrm{ral}^{18}$ do cenário brasileiro iniciado a partir do governo Collor.

Tal mal-estar diz respeito, em especial, às macro-políticas que enfraquecem o Estado, figura chave no olhar estratégico consolidado na Instituição ao longo de sua história. Em decorrência, os discursos de alerta aos perigos da globalização se sucedem na fala de seus porta-vozes.

Os sintomas deste mal-estar incluem (1) a sensação de perda de soberania;, ${ }^{19}$ (2) a falta de um projeto nacional ${ }^{20}$ - e a discreta revolta à desconsideração da Autoridade para com a doutrina da ESG, (3) a denúncia do neo-colonialismo ${ }^{21}$ dos países do norte; e (4) a desconfiança ${ }^{22}$ com relação a internacionalização da economia nacional.

As avaliações estratégicas do novo mundo são discretamente tecnófobas, ${ }^{23}$ pois argumentam para a necessidade de se adequar as inovações de além-mar às características do Brasil; irritadiças com o novo predomínio dos Estados Unidos, ${ }^{24}$ seus ataques estratégicos e militares a países em desenvolvimento (como ao Haiti, Iraque e Panamá e o apartheid ${ }^{25}$ nuclear que deseja afastar nações como o Brasil do direito de desenvolver know-how nesta sensível área), assim como a seus argumentos falsamente redentores demandando livre-comércio; e, finalmente, as avaliações críticas dos pensadores do establishment militar brasileiro ao atual contexto descrito como de guerra econômica ${ }^{26}$ e cultural ${ }^{27}$ entre os países do norte e sul. ${ }^{28}$

Portanto, deduz-se que aos olhos da ESG o novo panorama emergente e o processo de privatização estão sob judice. ${ }^{29} \mathrm{O}$ clima na Instituição, considerando sua documentação, é de reação veemente à idéia do Estado Mínimo. ${ }^{30}$ Tal reação é, quanto à forma, apartidária, muito embora razoavelmente uníssona na argumentação de seus porta-vozes, discretamente enlutados de uma era que se foi e que se revelava mais segura de si quanto a propósitos nacionais, óbices, diagnósticos e projetos de desenvolvimento (conforme a terminologia própria da ESG).

Infere-se de tais manifestações, por vezes indiretas e protegidas pelo tom acadêmico dos estudos de seus scholars, que o poder do Estado brasileiro ficou gravemente fragilizado ao perder o controle das telecomunicações. ${ }^{31}$

Há, no entanto, algumas vozes minoritárias nesta comunidade que acolhem o novo mundo. O general de Exército Rubens Bayma Denys chega a afirmar que "é preciso que se impeça, porém, que os padrões desta tão ansiada retomada do desenvolvimento sejam moldados em experiências do passado, calcadas em irresistível parceria da iniciativa privada com os cofres do tesouro". 32

Segundo seu ponto de vista, o Estado deve recuar e "abrir espaços à sociedade economicamente organizada". O Estado que ele quer é mais normativo e fiscalizador.

Outra opinião, a do Coronel Aviador Newton de Goes Orsini de Castro, advogava em 1995 a imediata privatização da economia. ${ }^{33} \mathrm{Na}$ mesma direção se encaminhava José da Cunha Faria ao afirmar que "precisamos de mais Brasil e menos Brasília". ${ }^{34}$ O "Contrato com o Brasil", documento já referido, acolhe igualmente em seu artigo quarto o espírito deste novo tempo. ${ }^{35}$

Tais vozes não constituem, no entanto, o mainstream intelectual vigente na ESG na 
atual conjuntura, conforme se observa na grande maioria dos autores alinhados em suas publicações e das falas de suas principais autoridades.

Entre as poucas manifestações de setores militares à imprensa, antes ainda das privatizações das empresas estatais de telecomunicações, o ex-comandante da ESG, brigadeiro Sérgio Xavier Ferolla, dizia ${ }^{36}$ que o "tronco central" da Embratel não poderia ser quebrado, pois temia que o monopólio estatal passasse necessariamente ao controle de um monopólio privado. Tal argumentação foi reforçada em suas repetidas aparições na TV Manchete depois das privatizações do sistema Telebrás, em abril de 1999. Noutra oportunidade, em julho de 1998, Gustavo Franco, ex-presidente do Banco Central, foi intensamente provocado por 80 militares durante sua palestra na ESG. Os presentes acusaram o Governo de perder a soberania na condução da economia. ${ }^{37}$

Muito embora os interesses operacionais dos militares estejam protegidos na nova estrutura, ${ }^{38}$ a queixa recorrente refere-se ao desvio de rota empreendida nas políticas da Autoridade, e que contrariam a doutrina nacionalista da ESG.

\section{Conclusão e discussão}

Sob a promessa de dar novo fôlego ao desenvolvimento do País, a privatização das empresas de telecomunicações constituem um duro golpe nos princípios que nortearam a implantação de novas tecnologias de telecomunicação a partir da iniciativa do Estado, pois contraria o entendimento da ESG de concentrar os setores estratégicos sob o domínio de empresas públicas.

Como afirmado alhures, ${ }^{39}$ o tema da privatização das telecomunicações não é nem a última palavra, nem a derradeira cena. Considerando a história pregressa aqui referida de ação direta dos militares em decisões relativas a políticas de desenvolvimento, este modelo poderá eventualmente se alterar.
Este ziguezague tem se constituído na marca registrada da história das telecomunicações brasileiras, e como se vê, tem saudosos adeptos entre os estrategistas nacionais assim como a simpatia de importantes círculos políticos à esquerda e à direita do espectro ideológico.

Na nova conjuntura, a ESG não abdicou de sua obra e mantém-se firme apoiada em sua doutrina..$^{40}$ Em decorrência, infere-se destes discursos que segurança nacional eqüivale, na nova Era da Informação e segundo este ponto de vista, na recuperação do poder do Estado como ente capaz de agir "em benefício da coletividade" e de afirmar "a soberania brasileira" sobre seu espaço geográfico, econômico e cultural.

Cabe saber agora que formas esta comunidade da caserna encontrará para influenciar as políticas do governo sem, como no passado, se desrespeite as regras do jogo democrático. É de se prever, em decorrência, que a sensação de frustração pelo poder perdido com o distanciamento da arena política deverá resultar no médio prazo em novas formas de interação com o poder cívil. E neste cenário restará ao estrategista menos a coerção e mais o convencimento e a persuasão como armas à sua disposição .

\section{Notas}

1 Jornalista, Mestrando, FAMECOS/PUCRS.

2 Professor, FAMECOS/PUCRS; Pesquisador do CNPq.

3 O exemplo mais evidente deste interesse são as expedições do Marechal Rondon e seu esforço em expandir a telegrafia e unir as fronteiras com as áreas urbanas.

4 Como veremos adiante, essas intervenções podem ser verificadas bem antes disso, ainda no século XVI.

5 Azevedo, Fernando de. A Cultura Brasileira. $5^{\mathrm{a}}$ edição, São Paulo, Melhoramentos, Editora da Universidade de São Paulo, 1971.

6 Silva, Edmundo de Macedo Soares. "O Problema das Co- 
municações". 0 Observador Econômico e Financeiro, no 166, Novembro, 1949, pp. 54-64.

7 Azevedo, op. cit., pp. 279-314.

8 Ibid, p. 280.

9 Silva, op. cit. p.58.

10 Ibid, p. 59.

11 Ibid, p. 60.

12 VVAA. História do Exército Brasileiro: Perfil Militar de um Povo. Brasília e Rio de Janeiro, Edição do Estado-Maior do Exército, (sem data), p. 791.

13 Tavares, Aurélio de Lyra. "A Integração Nacional". Segurança e Desenvolvimento. $\mathrm{n}^{0} 177,1979$, p. 22.

14 Metas e Bases para a Ação do Governo - Presidência da República -, setembro de 1970, citado por Miceli, Sérgio, in A Noite da Madrinha. São Paulo, Perspectiva, 1972.

15 II PND (Plano Nacional de Desenvolvimento).

16 Siqueira, Ethevaldo. "A Volta da Esperança". RNT - Revista Nacional de Telemática. n 183, novembro, 1994, p. 6.

17 Ibid, p. 6.

18 Antonio da Luz Costa, "Globalização", Revista da ESG, ano XI, n.30, 1995, pp: 161-178.

19 Marcos Henrique C. Côrtes, "Fundamentos das relações internacionais e conceitos de atuação no campo externo", Revista ESG, ano XII, n.35, 1997, pp: 147-185.

20 Roberto Cavalcanti de Albuquerque, "Reforma do Estado e Governabilidade", Revista ESG, ano X, n. 27, 1994, pp: 43-56; Ver também Ferolla, Ibid, p. 10. Ver op.cit, p. 176; Juracy da Silva, "O Brasil e a nova ordem mundial", Segurança e Desenvolvimento, ano XLI, n.212, 1992, p.38; Hernani Goulart Fortuna, "O desafio brasileiros nos anos 90", Revista ESG, ano IX, n.24, 1993, p. 22.

21 Marcos Oliveira. "Nova Ordem, Velhos Problemas", Revista ESG, ano X, n.29, 1994, pp: 101-121.

22 Ibid supra 23, p. 12.
23 Sérgio Xavier Ferolla, "O impacto da economia globalizada na ciência e tecnologia", Revista ESG, ano XII, n.37,1998, p. 103.

$24 \mathrm{Ibid}$

25 Ibid. A mesma idéia já aparecia em Luiz Sérgio Silveira Costa, "A complexa nova ordem mundial", Revista ESG, ano X, n.29, 1994, pp:37-63.

26 Sérgio Xavier Ferolla, "Bases para um projeto nacional", Revista ESG, ano X, n.27,1994, p. 9.

27 Predomina a ambigüidade em vários discursos no que se refere aos avanços das novas e mais eficientes formas de telecomunicação. As antenas ligaram o Brasil ao mundo fragilizando como efeito decorrente o poder de controle natural antes exercido pelo relativo isolamento das fronteiras às mensagens de além-mar. 0 Vice-Almirante e ex-diretor da Escola de Guerra Naval , Carlos de Meira Mattos, um dos autores mais freqüentes da Revista da ESG e especialista reconhecido nos estudos geopolíticos brasileiros afirma: "A invasão indiscriminada dos meios eletrônicos, comandados pelos países mais desenvolvidos, a todas as nações, coloca e xeque o controle dos estados sobre suas fronteiras. Surge então a tese da Globalização do Planeta, da sociedade unificada pela invasão, cada vez maior, dos meios de comunicação eletrônicos, pela rapidez dos transportes e pela incapacidade do estado-nação controlar esta interferência forânea." Revista ESG, ano XII, n.34, 1997, p.98.

28 Tal percepção é compartilhada por Samuel P. Huntington, autor de 0 Choque de Civilizações. Em seu artigo "The Lonely Superpower" (Foreign Affairs, Março/Abril 1999, pp. 35-49) ele critica acidamente a política externa dos Estados Unidos por ter-se mostrada indisposta em estabelecer alianças com potências regionais. Ele inclui o Brasil nesta categoria. "Virtually all major regional powers are increasingly asserting themselves to promote their own distinct interests, which often conflict with those of the United States." (p. 37).

29 Supra 30, p. 105.

30 Supra 23, p. 44.

31 É o que se observa nas sutis considerações de Ferolla, em 
supra 30, p.105: "Contrariamente às indústrias que visam o grande público, nas quais se buscam grandes quantidades a baixos custos, quando um país investe em áreas de interesse estratégico enfoca qualidade e confiabilidade, não tendo significado quantificar as pequenas séries e suas aplicações (aviões, foguetes, satélites, supercomputadores, radares, etc.) e cabendo ao estado, de forma clara ou dissimulada arcar com o suporte financeiro para tais Programas, como ocorre, geralmente, nos países industrialmente desenvolvidos."

32 "O Estado e o desafio da modernização/privatização nos transportes." Segurança e Desenvolvimento, ano XLIII, n. 216, 1994, p. 28.

33 "A presente conjuntura e o Plano real", op.cit, pp. 43-44.

34 "Os governos devem inspirar e liderar transformações que a sociedade, efetivamente, deseje e se mobilize para alcançá-las. Nenhum projeto ou governo por si só pode resolver os problemas da sociedade, somente a própria, pode resgatar-se a si mesmo." In "Projeto de Reconstrução Nacional", Revista ESG, ano VI, n.17, 1991, p.79.

35 "O redimensionamento do estado através da eliminação de seu caráter intervencionista como agente econômico, e da adoção de uma descentralização administrativa que busque a co-participação da iniciativa privada nas atividades que esta possa exercer, transferindo para os estados e municípios aquelas atribuições que melhor possam ser exercidas por estes, em proveito de suas populações que, por sua vez, têm melhores condições de fiscalizá-las."

36 Folha de São Paulo, 15/3/94.

\section{Estado de São Paulo, 17 de julho de 1998, Ed. Economia.}

38 As empresas que assumiram a Embratel se comprometeram a manter privilégios concedidos a órgãos de segurança. Nesta lista de clientes especiais estão a Presidência da República, o Emfa, o Exército, a Marinha e a Aeronáutica, 0 ministério da Justiça, a Polícia Federal, as polícias militares e os bombeiros. As Forças-Armadas do Brasil pretendem na verdade fazer uso no futuro de um satélite de comunicação exclusivo. Hoje a Embratel aluga quatro canais independentes, três para cada uma das Forças e o Siscomis (Sistema de Comunicações Militares por Satélite), que está sob controle do Emfa, faz parte da Estrutura Militar de Guerra e interliga os sistemas das três forças e a estrutura da Presidência. Folha de São Paulo, 1/8/98. Gazeta Mercantil, 22 de maio de 1998.

39 Wainberg, Jacques A . "Luta corpo a corpo: a ambígua relação com estrangeiros pelo controle das telecomunicações do Brasil". (In Revista Comunicação e Sociedade, no prelo).

40 Há alguns significativos adendos ao trabalho exegético que seus pesquisadores têm realizado sobre a doutrina oficial da Instituição. Eles acrescentaram, por exemplo, a justiça social como meta estratégica prioritária do país, ao lado da segurança e desenvolvimento.

\section{Referências}

AZEVEDO, Fernando de. A Cultura Brasileira. $5^{a}$ edição, São Paulo, Melhoramentos, Editora da Universidade de São Paulo, 1971.

BULIK, Linda. Doutrinas da Informação: no Mundo de Hoje. São Paulo, Edições Loyola, 1990.

COSTA, Samuel Guimaraes da. Formação Democrática do Exército Brasileiro: Pequena Tentativa de Interpretação Social. Rio de Janeiro, Editora Biblioteca do Exército, 1957.

CASTRO, Terezinha de. "Comunidade Econômica Européia: Federação ou Confederação". A Defesa Nacional, n ${ }^{0} 761$, julho/setembro, 1993.

CORBISIER, Roland. Formação e problema da cultura brasileira. MEC. 1958.

COSTA, Samuel Guimaraes da. Formação Democrática do Exército Brasileiro: Pequena Tentativa de Interpretação Social. Rio de Janeiro, Editora Biblioteca do Exército, 1957.

COMBLIN, Pe. Joseph. A ideologia da Segurança Nacional: 0 poder militar na América Latina. Civilização Brasileira. RJ, 1978.

FEROLLA, Sérgio Xavier. "Março de 64: uma Visão Histórica". Folha de São Paulo. 28 de março, 1994.

GEROMEL, Sérgio Antônio. "As Comunicações na Época da Missão Francesa". A Defesa Nacional, n ${ }^{0} 762$, outubro/dezembro, 1993. 
MATTOS, Sérgio. The Impact of 1964 Revolution on Brasilian Television. San Antonio, Texas, 1982.

MICELI, Sérgio. A Noite da Madrinha. São Paulo, Perspectiva, 1972.

OLIVEIRA, Euclides Quandt de. Renascem as Telecomunicações. São José dos Pinhais, Ditel Gráfica e Editora, 1992.

OLIVEIRA, Euclides Quandt de. A televisão no Brasil. Brasília, Gráfica do Senado, 1975.

OLIVEIRA, Euclides Quandt de. A Televisão como Meio de Comunicação de Massa, Brasília, Gráfica do Senado, 1974.

OLIVEIRA, Euclides Quandt de. Política de Comunicações. Ministério das Comunicações, 1976.

PEREIRA, Edvaldo Simas. "Telefone: Uma Crise da Época à Espera de Solução". O Observador, n'. 247, setembro, 1956.

SENA, Ernesto. Rascunhos e Perfis. Coleção Temas Brasileiros. Brasília, Editora Universidade de Brasília, 1983.

SILVA, Edmundo de Macedo Soares e. "O Problema das Comunicações". 0 Observador Econômico e Financeiro, no 166, Novembro, 1949, pp. 54-64.

SILVA, João Luiz Martins Ney da. "Informática e Desenvolvimento". Segurança e Desenvolvimento. Rio de Janeiro, $n^{0} 145$, ano XX, 1971, pp. 121-133.

SIQUEIRA, Ethevaldo. "Telecomunicações, receita para vencer a crise". Engenharia na Indústria. n" 21, II Congresso Brasileiro de Telecomunicações, setembro, 1976.

SODRÉ, Nelson Werneck. A História Militar do Brasil. $3^{a}$ edição, Rio de Janeiro, Civilização Brasileira, 1979.

WAINBERG, Jacques. "Telecomunicação e a Nação-Potência dos Trópicos". In: VVAA, Temas Contemporâneos em Comunicação. I Colóquio Brasil Dinamarca de Ciências da Comunicação, realizado durante o XIX Congresso Intercom, Londrina, 1996, Org. Maria Immacolata Vassalo de Lopez, São Paulo, Edicon, pp. 63-87.

TAVARES, Aurélio De Lyra. "A Integração Nacional". Segurança e Desenvolvimento. Rio de Janeiro, $\mathrm{n}^{0}$ 177, ano XXVIII, 1979.
TAVARES, Aurélio De Lyra. Segurança Nacional, Antagonismos e Vulnerabilidades. Biblioteca do Exército. 1958.

TAVARES, Aurélio De Lyra. Telecomunicaçẽes e Segurança Nacional: História e Atualidade. Biblioteca do Exército. 1959.

Periódicos e documentos:

Ministério das Comunicações, Anuário 1984.

Painel Internacional Telebrasil, outubro de 1981.

I Plano de Desenvolvimento (IPND) 1972/1974.

II Plano de Desenvolvimento (II PND) 1975/1979.

II Plano Brasileiro de Ciência e Tecnologia, 1976.

III Plano Brasileiro de Ciência e Tecnologia, 1983. 